\title{
Radiation Hormesis: Historical and Current Perspectives
}

\author{
Jonathan Baldwin, CNMT, RT(CT), and Vesper Grantham, RT(N), CNMT \\ Department of Medical Imaging and Radiation Sciences, College of Allied Health, University of Oklahoma Health Sciences Center, \\ Oklahoma City, Oklahoma
}

\begin{abstract}
CE credit: For CE credit, you can access the test for this article, as well as additional JNMT CE tests, online at https://www.snmmilearningcenter.org. Complete the test online no later than December 2018. Your online test will be scored immediately. You may make 3 attempts to pass the test and must answer $80 \%$ of the questions correctly to receive $1.0 \mathrm{CEH}$ (Continuing Education Hour) credit. SNMMI members will have their CEH credit added to their VOICE transcript automatically; nonmembers will be able to print out a CE certificate upon successfully completing the test. The online test is free to SNMMI members; nonmembers must pay $\$ 15.00$ by credit card when logging onto the website to take the test.
\end{abstract}

\begin{abstract}
The purpose of this article is to provide the reader with a better understanding of radiation hormesis, the investigational research that supports or does not support the theory, and the relationship between the theory and current radiation safety guidelines and practices. The concept of radiation hormesis is known to nuclear medicine technologists, but understanding its complexities and the historical development of the theory may bring about a better understanding of radiation safety and regulations.
\end{abstract}

Key Words: radiation hormesis; radiation safety; radiation response

J Nucl Med Technol 2015; 43:242-246

DOI: 10.2967/jnmt.115.166074

\section{H}

ormesis is the concept that biologic systems can respond in a positive way, or be stimulated by, physical or biologic exposure to low doses of an agent that is toxic at higher doses (1). Additionally, hormesis is defined as "any physiological effect that occurs at low doses which cannot be anticipated by extrapolating from toxic effects noted at high doses" (2). Therefore, radiation hormesis is the theory that biologic systems can respond positively to exposure to low doses of ionizing radiation.

In contrast to the hormesis theory, much of the radiation safety that we, as nuclear medicine technologists, practice follows a different model. A brief discussion of doseresponse models is required to help the reader understand the differences between the linear no-threshold, threshold, and hormetic models that will be discussed in this article. The linear no-threshold model states that biologic effects increase as exposure to the physical or biologic agent increases (Fig. 1A). The threshold models states that no sig-

\footnotetext{
Received Aug. 25, 2015; revision accepted Oct. 2, 2015.

For correspondence or reprints contact: Vesper Grantham, University of Oklahoma Health Sciences Center, 1200 N. Stonewall Ave., AHB 3021,

Oklahoma City, OK 73117

E-mail: vesper-grantham@ouhsc.edu

Published online Nov. 19, 2015.

COPYRIGHT (C 2015 by the Society of Nuclear Medicine and Molecular Imaging, Inc.
}

nificant biologic response is observed until exposure to the physical or biologic agent reaches a threshold dose (Fig. 1B). The hormetic model states that low-dose exposure to a physical or biologic agent helps the body and that as the dose increases the benevolent effects decrease. The hormetic model takes on a linear appearance at higher doses, and biologic damage is determined by increasing dose (Fig. 1C).

In the United States, the Nuclear Regulatory Commission is the governing body that sets limits and enforces laws concerning the safe use of radiation (3). These regulations on radiation safety assume that radiation follows a linear no-threshold model and that the biologic effects of radiation relate linearly to dose (2). Radiation protection is based on a linear no-threshold model, and dose effects at low levels are extrapolated from effects observed in atomic bomb survivors, Chernobyl disaster survivors, and other populations with documented high exposure rates (4). The hormesis theory is the subject of substantial research to evaluate the ongoing question of whether radiation continues this linear relationship at low doses or has a different effect. An analysis of the literature demonstrates that both radiation science and toxicology may relate to hormetic effects, with numerous epidemiologic studies supporting the theory of radiation hormesis; however, the theory has not found mainstream acceptance. The goal of this article is to help the reader better understand the concept of radiation hormesis and the literature supporting or not supporting the theory.

\section{HISTORY}

In the late 1800 s, the discovery of x-rays by Wilhelm Roentgen, radioactivity by Henri Becquerel, and radium by Pierre and Marie Curie birthed the study of radiation effects on living things (3). Radiation was first seen as benign and not dangerous and was used for many personal applications. Radioactive sources, radium especially, could be found in multiple everyday products (5). There were different radioactive creams that promised skin rejuvenation, and there were radioactive elixirs promising to rid the body of toxins and disease (5). Following the observed harmful effects of radiation, the perception of radiation changed. Becquerel and Pierre Curie both sustained radiation burns from their own experiments, and it is thought that Marie Curie, as well 


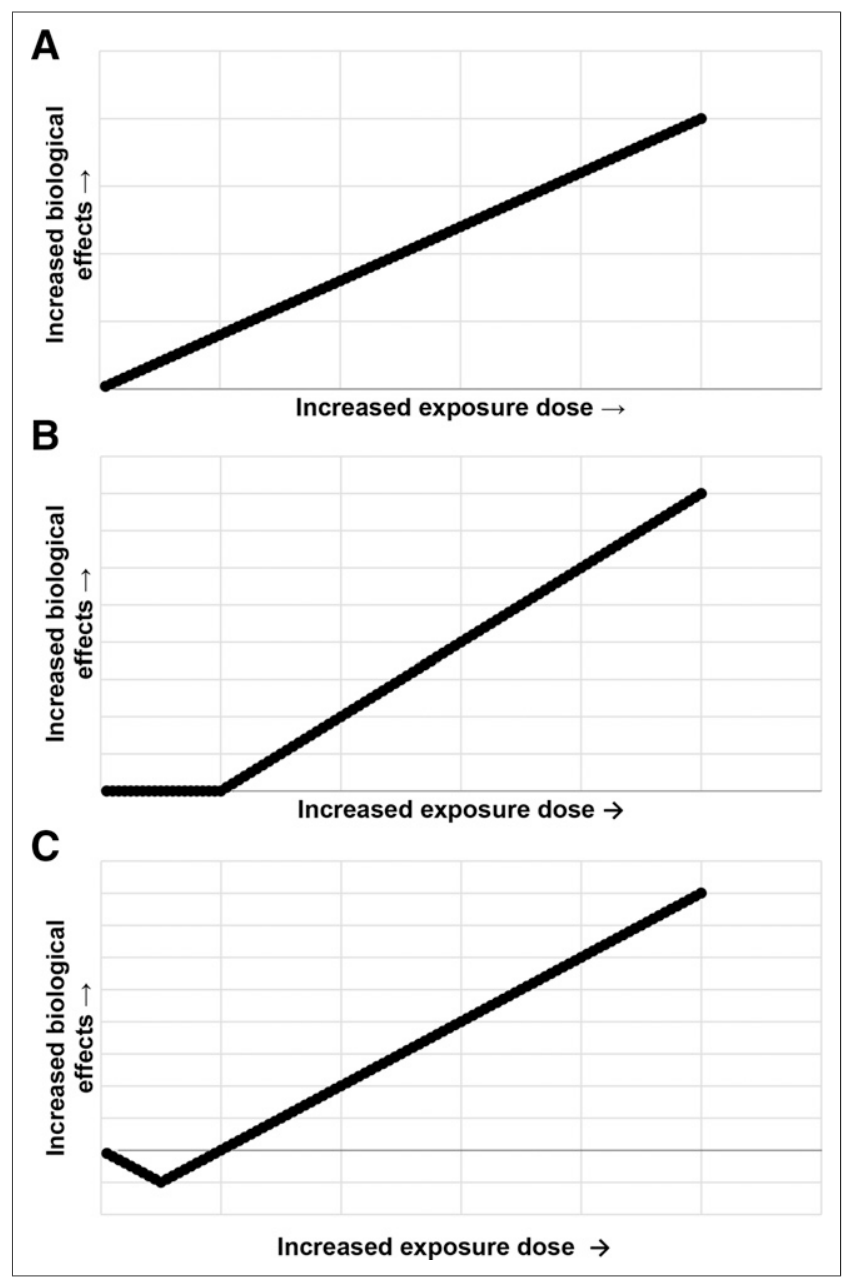

FIGURE 1. Example of linear no-threshold model (A), threshold model (B), and hormetic model (C).

as her daughter, died of leukemia from exposure to radiation in their experiments (3). Also, the death of Eben M. Byers, a wealthy Pennsylvania industrialist, caught public attention. Byers had been taking radioactive elixirs for "rejuvenation," and these were linked to his death (6). The evident dangers of radiation were observed, and public opinion began to inquire about what levels of radiation are safe.

The bombings of Hiroshima and Nagasaki in August 1945 had a great impact on the perception of radiation. Many of the studies that focused on beneficial uses of radiation stopped, and the focus shifted to investigating the effects of radiation exposure and determining safe levels of radiation. Investigators focused on building a radiation dose-response curve, which demonstrates the relationship between the biologic effects of radiation as dose increases (6). The data that were used to describe the effects of radiation on an individual were collected primarily from the survivors of the atomic bombings and other nuclear industrial workers (6). Studies were conducted to determine a dose of radiation that was safe or had no effect, also called a threshold dose (6). Because scientists and officials could not prove, using the high-dose atomic bombing data, that such a relationship existed, the response at high doses was extrapolated to low doses, and the linear nothreshold model was accepted (6). The linear no-threshold model assumes there is no safe level of radiation, or that all radiation is damaging (7). Radiation regulatory agencies adopted this model, on which many of the regulations and guidelines were based. Around the same time, threshold and hormetic models were studied in other professional fields. In fact, toxicologic studies discovered the interesting relationship between the dose of a toxicant and the biologic response to that toxicant (8). These studies are important to radiation hormesis, because the data demonstrate that most environmental exposure does not normally produce the linear response in the body that the linear no-threshold model assumes (8).

Years before the discovery of radiation, and through the early 1900s, advances in the toxicology field demonstrated that variable doses of toxic substances either showed no effect or in some cases had a beneficial effect (9). Professor Hugo Schulz, who worked at the University of Greifswald in Germany in the late 1800 s, observed that at low dosages various chemical and biologic toxicants appeared to stimulate metabolism (9). His work became known as the Arndt-Schulz law, which states, "Weak stimuli accelerate vital activity, medium ones promote it, strong ones inhibit it, and very strong ones snuff it out." (8). This relationship was also seen in the work of Ferdinand Hueppe and became known as Hueppe's rule (9). Because of this research, as well as governmental concern about high-dose effects and the difficulty of proving low-dose effects, the idea of hormesis began to fade and threshold models became better accepted in toxicology (9). The main difference between hormetic models and threshold models is that in a threshold model, doses below the threshold show no toxic effect whereas in a hormetic model, doses below a certain level may actually stimulate and promote a hormetic physiologic response (9). Many pharmaceuticals, vitamins, and even toxicants have been shown to have hormetic effects at low levels but toxic effects at high levels $(8,10)$. These results in the toxicology field sparked research on the possibility of hormetic or threshold effects with radiation.

\section{RADIATION HORMESIS INVESTIGATIONS}

From the time that the x-ray was discovered until the mid1940s, the idea of the hormetic effects of radiation was supported by the scientific literature, and public opinion of radiation was positive for the most part $(1,6)$. Various plant studies showed hormetic responses to low doses of x-rays ( 1 ). Plant seeds were exposed to radiation, and many of those plants responded with increased yields of soy, wheat, and flax (1). Also, radiation demonstrated therapeutic effects on various types of skin disease (6). With the implementation of the linear no-threshold model, a great deal of the research into radiation hormesis stopped and radiation scientists became separated into 2 divisions, those who supported the linear no-threshold model and those who supported different models (6). Scientists who favor the hormetic response at low doses are also divided on why these effects may occur. For example, 
there is one theory that radiation stimulates DNA repair, another theory that radiation brings about free-radical detoxification, and a third theory that radiation stimulates the immune system (6). Advocates of both sides have theories as to what really happens to biologic tissue at low doses of radiation. There have been multiple studies through the years on the effects of radiation at lower doses, and many of these studies can be explored in the works of Calabrese and Baldwin $(1,10)$. The current article will further describe 3 areas of investigation into radiation hormesis: research supporting the possibility of hormetic effects from low-dose radiation, research showing no hormetic effects, and research on why the radiation hormesis model has not been widely accepted.

\section{SUPPORTIVE INVESTIGATIONS INTO RADIATION HORMESIS}

As technology has progressed, the ability to study effects at the cellular level has increased. Modern interest in the theory of radiation hormesis regained momentum during the 1980s. One investigation studied the reproduction of protozoans under the effects of low-dose ionizing radiation (11). That study examined the reproduction and growth rates of T. pyriformis when exposed to radiation levels below the background level, at the background level (the background control rate), and above the background level (2 low rates, 7.3 and $45 \mathrm{mrad} / \mathrm{d}$ ). When radiation was below the background level, the reproduction rate was lower than the background control rate $(P<0.01)$, and at both levels of above-background radiation, the reproduction rate was higher than the background control rate $(P<0.01)$. More recent studies into the effects of low levels of radiation have been conducted, many with similar results.

During the mid-1990s, Cohen analyzed lung cancer mortality rates in 1,601 counties across the United States and compared these rates to radon exposure levels (12). After controlling for smoking prevalence and many other confounders, he found that as the low-level radon dose increased, lung cancer mortality decreased. These results were the opposite of the expected increase in lung cancer mortality with increased radon exposure. Also, in a 2002 review of the hormesis literature, Cohen stated that "The evidence in this review leads to the conclusion that the linear no-threshold theory fails badly in the low dose region..." (13). The literature in the Cohen review demonstrated evidence that low $(<50$ cGy) radiation levels increase immune response, which helps the body fight DNA double-strand breaks due to radiation or other causes (13). Also, the literature in the review indicated a $20 \%$ probability that the slope of the dose response curve could be negative at lower doses. These points were later again supported by a 2004 study involving mice.

In 2004, Li et al. demonstrated that low doses ( $75 \mathrm{mGy}$ ) of radiation stimulated bone marrow hematopoietic progenitor cells in mice (14). These cells help the body regulate the amounts of the various blood cells in the body, and stimulation of these cells may increase blood cell counts in patients undergoing therapy (14). A 2005 study contrasted the similarities between toxicologic response and radiation response at low dose levels (15). That study concluded that doses below $200 \mathrm{mGy}$ stimulate DNA repair mechanisms and produce a positive response by cells; therefore, the linear no-threshold model does not describe the relationship at low levels and a combination of curvilinear models should possibly be used. $\mathrm{Yu}$ et al. studied the effects of low-dose radiation on mice implanted with sarcoma (16). That study found a lower tumor occurrence rate in irradiated mice than in nonirradiated mice $(P<0.05)$. Also, the growth of sarcoma was slower in the mice exposed to the low radiation dose. The overall results indicated that low-dose radiation has the potential to decrease tumor formation and increase immune function.

In addition to the mentioned investigations, some studies conducted within the past year have had interesting results. In early 2015, Kudryasheva and Rozhko reviewed the effect of low-dose particulate ( $\alpha$ and $\beta$ ) radiation on luminous marine bacteria (17). That review included multiple studies investigating the effects of ${ }^{3} \mathrm{H},{ }^{241} \mathrm{Am},{ }^{235} \mathrm{U}$, and ${ }^{238} \mathrm{U}$ on bioluminescent bacteria. The review concluded that in the presence of low-dose radiation, the bacteria showed adaptive characteristics attributable to radiation hormesis. In another study, the U.S. population was grouped into high-impact states and low-impact states based on where nuclear weapon testing occurred (18). The study found that lung cancer incidence in both men and women was lower $(P<0.001)$ in highimpact states than in low-impact states. This result correlates with an Argonne National Laboratory study from 1973 that also found lower cancer rates in states with higher background radiation (19).

\section{NONSUPPORTIVE INVESTIGATIONS INTO RADIATION HORMESIS}

Not all data in the above studies favor the theory of radiation hormesis. The previously mentioned 2000 review by Calabrese and Baldwin also included data that contradicted the theory (1). Multiple plant studies showed negative or inhibitory effects from low-dose radiation. The authors did comment that this early research may not have accounted well for the different ways in which plant species respond to variable doses of radiation.

There also have been more modern investigations that shed doubt on the theory of hormesis. Many of the modern investigations that found contradictions to the radiation hormesis theory assessed DNA breakage and repair. A 2003 study investigated DNA double-strand breaks in human lung cells after exposure to variable doses of $\mathrm{x}$-irradiation ( $\leq 200 \mathrm{mGy}$ ) (20). When it came to repair of the doublestrand breaks, no stimulatory response was found, indicating that the linear no-threshold model may underestimate the effect at low doses. Another study, by Spencer et al. in 2004, focused on the effects of low levels of radiation on DNA repair mechanisms in human cells (21). ATM (ataxia telangiectasia mutated) and histone $\mathrm{H} 2 \mathrm{~A}$, which are active in DNA damage recognition and repair, were studied under low-dose radiation. In cells that received the radiation, activation of ATM 
was lowered by $40 \%-50 \%$ and histone H2A levels were lowered as well. A more recent study, from 2014, further reinforced the findings from the previous literature (22). The DNA double-strand breaks in mice were found to be repaired at the same rate in cells that received low-dose radiation as in those that did not. These studies are just a few of the investigations demonstrating a possible flaw in the theory of radiation hormesis.

\section{REASONS FOR THE LIMITED ACCEPTANCE OF RADIATION HORMESIS}

There are many ideas as to why the radiation hormesis model has been suppressed politically and the linear nothreshold model considered the norm. The history presented earlier in this article gives a foundation on the political and social reasons why the theory of radiation hormesis is not widely accepted. Calabrese and Baldwin indicated that the reasons radiation hormesis has not been given much consideration include the challenges of experimentation, unawareness of toxicologic hormesis research, scientific criticism, and the economic implications (23). Assessing differences between background radiation and low-dose radiation is difficult because the stimulatory response dose is close to background levels (21). When the linear no-threshold model was adapted in the 1940s, the limitations of the measuring devices at that time made it quite challenging to discriminate these small differences, and even though toxicologic research showed hormetic relationships between various known toxicants at low levels, radiation scientists did not relate radiation to these toxicants (23). In addition, many of the early studies had inconsistent results. Some studies showed a stimulatory response to low-dose radiation, whereas others showed an inhibitory response (1). This inconsistency caused much critique from scientists at the time, and this criticism followed into documents to the Nuclear Regulatory Commission (23). Lastly, many companies took advantage of the discovery of radiation to make products that promised rejuvenation or agricultural increases (23). These companies profited from selling such products to the general public, and as noted above, with the death of Byers this practice became widely controversial $(6,23)$. Also, the linear no-threshold model may have sparked financial interest by radiation physicists. According to Brucer, "As soon as Health Physicists saw the money in radiation hysteria, the maximum permissible dose came down to background." (24). Public fear of radiation led to multiple radiation-shielding legislative decisions. Companies began to sell, and still do today, radiation-protective equipment such as lead aprons, portable shielding, and other radiation-absorbing devices (24). Another possible reason the hormesis theory lost support was that during many of the crucial years, the country was focused on fighting World War II (23). Radiation hormesis began to strongly lose momentum in the late 1930s and early 1940s (23). During that time, attention in many scientific fields shifted to research that would help the war effort, such as development of the atomic bomb. Also, in the post-World War II era large groups of Soviet scientists were studying the effects of low-dose radiation, but with the Cold War the availability of this research to the United States became limited. From the end of World War II until the late 1980s, the relationship between Western countries and the Soviet Union was tense. Because information from both sides was not shared, including research into the effects of radiation at low levels, much of the work of the Soviet scientists went unknown until long after radiation protection programs had been implemented in the United States.

The timing of this combination of factors affected scientific opinion on radiation hormesis, thus determining the theory's fate in the regulations (23). Many of the scientists who helped to form the Nuclear Regulatory Commission and determine the linear no-threshold model were not convinced that the hormesis theory was valid (23). Therefore, the linear nothreshold model was accepted for all doses of radiation (7). The idea that there is no safe dose of radiation has persisted since that time, even in the face of valid epidemiologic studies demonstrating findings consistent with radiation hormesis.

\section{CONCLUSION}

Radiation hormesis is the idea that low doses of radiation may stimulate or have a positive outcome on biologic tissue. Ever since the discovery of x-rays, scientists have been trying to determine the effects of radiation at different levels and whether there is a safe level of radiation. In the early years of research, the theory of radiation hormesis had scientific and public support. During the same time, many experiments in toxicology showed hormetic effects from various toxicants. Radiation scientists at the time failed to draw similarities between the radiation research and the toxicology research, and with the change in public opinion, scientific criticism, and other external factors, the theory of radiation hormesis lost momentum. The linear no-threshold model, based on highdose exposure, was accepted for application to radiation safety and dose effects.

Even though the no-threshold model is widely accepted, there has been a resurgence of literature investigating the theory of radiation hormesis, including valid epidemiologic studies on the relevance of radiation hormesis in plants, bacteria, fungi, and mammalian cells. These studies have demonstrated statistically significant differences for all the various cell types investigated when exposed to low doses of radiation. On the other hand, there have been studies indicating that low-dose radiation has no effect on, or even inhibits, repair of DNA double-strand breaks. Conflicting results from both sides of the radiation hormesis argument demonstrate that the exact effects at low radiation doses are not known. As radiation science moves forward, the validity of the linear no-threshold model at lower doses needs to be questioned and more research put into radiation hormesis.

\section{DISCLOSURE}

No potential conflict of interest relevant to this article was reported. 


\section{REFERENCES}

1. Calabrese EJ, Baldwin LA. Radiation hormesis: its historical foundations as a biological hypothesis. Hum Exp Toxicol. 2000;19:41-75.

2. Sagan LA. What is hormesis and why haven't we heard about it before? Health Phys. 1987;52:521-525.

3. Hall EJ. Radiobiology for the Radiologist. 5th ed. Philadelphia, PA: Lippincott Williams \& Wilkins; 2000.

4. Parsons PA. Radiation hormesis: an evolutionary expectation and the evidence. Int J Rad Appl Instrum A. 1990;41:857-860.

5. van Wyngaarden KE, Pauwels EKJ. Hormesis: are low doses of ionizing radiation harmful or beneficial? Eur J Nucl Med. 1995;22:481-486.

6. Macklis RM, Beresford B. Radiation hormesis. J Nucl Med. 1991;32:350-359.

7. Cherry SR, Sorenson JA, Phelps ME. Physics in Nuclear Medicine. 3rd ed. Philadelphia, PA: Saunders; 2003.

8. Sagan LA. Radiation hormesis: evidence for radiation stimulation and speculation regarding mechanisms. Int J Radiat Appl Instrum C Radiat Phys Chem. 1991;37: 313-317.

9. Calabrese EJ. Hormesis: changing view of the dose-response, a personal account of the history and current events. Mutat Res. 2002;511:181-189.

10. Calabrese EJ, Baldwin LA. Chemical hormesis: its historical foundations as a biological hypothesis. Toxicol Pathol. 1999;27:195-216.

11. Luckey TD. Ionizing radiation promotes protozoan reproduction. Radiat Res. 1986;108:215-221.

12. Cohen BL. Test of the linear-no threshold theory of radiation carcinogenesis for inhaled radon decay products. Health Phys. 1995;68:157-174.

13. Cohen BL. Review: cancer risk from low-level radiation. AJR. 2002;179: 1137-1143.
14. Li W, Wang G, Cui J, Xue L, Cai L. Low-dose radiation (LDR) induces hematopoietic hormesis: LDR-induced mobilization of hematopoietic progenitor cells into peripheral blood circulation. Exp Hematol. 2004;32:1088-1096.

15. Feinendegen LE. Evidence for beneficial low level radiation effects and radiation hormesis. Br J Radiol. 2005;78:3-7.

16. Yu HS, Liu ZM, Yu XY, Song AQ, Liu N, Want H. Low-dose radiation induces antitumor effects and erythrocyte system hormesis. Asian Pac J Cancer Prev. 2013;14:4121-4126.

17. Kudryasheva NS, Rozhko TV. Effect of low-dose ionizing radiation on luminous marine bacteria: radiation hormesis and toxicity. J Environ Radioact. 2015;142:68-77.

18. Lehrer S, Rosenzweig KE. Lung cancer hormesis in high impact states where nuclear testing occurred. Clin Lung Cancer. 2015;16:152-155.

19. Frigerio NA, Eckerman KF, Stowe RS. Carcinogenic Hazard from Low Level, Low-Rate Radiation, Part I. Report ANL/ES 26. Argonne, IL: Argonne National Lab; 1973.

20. Rothkamm K, Löbrich M. Evidence for a lack of DNA double-strand break repair in human cells exposed to very low x-ray doses. Proc Natl Acad Sci USA. 2003;100:5057-5062.

21. Collis SJ, Schwaninger JM, Ntambi AJ, et al. Evasion of early cellular response mechanisms following low level radiation-induced DNA damage. J Biol Chem. 2004;279:49624-49632.

22. Blimkie MSJ, Fung LCW, Petoukhov ES, Girard C, Klokov D. Repair of DNA double-strand breaks is not modulated by low-dose gamma radiation in C57BL/ 6J mice. Radiat Res. 2014;181:548-559.

23. Calabrese EJ, Baldwin LA. Radiation hormesis: the demise of a legitimate hypothesis. Hum Exp Toxicol. 2000;19:76-84.

24. Brucer M. A Chronology of Nuclear Medicine. St. Louis, MO: Heritage Foundation; 1990. 